\title{
Laboratory parameters of $\beta$ thalassemia minor patients visiting BPKIHS as diagnosed by Agarose Gel Electrophoresis
}

\author{
Sherchand O, KC. R, Majhi S, Lamsal M, Baral N \\ Dept of Biochemistry, B.P. Koirala Institute of Health Sciences, Dharan, Nepal
}

Correspondence address: Dr. Ojaswee Sherchand, Department of Biochemistry, B.P. Koirala Institute of Health Sciences, Dharan, Nepal.

Email: drojasweesherchand@hotmail.com

\begin{abstract}
Introduction: Thalassemia is one of the most common genetic disorders worldwide. The current study aims at various laboratory parameters including agarose gel electrophoresis (AGE) pattern of patients consistent with clinical symptoms of $\beta$ thalassemia minor.

Methods: A total of 78 blood samples collected from patients visiting BPKIHS, Dharan to workup for anemia and red blood cell indices. From these 78 patients, 8 samples were suspected of $\beta$ thalassemia minor and were included in the study. The patients were divided in two groups, adult above 15 years of age and children less than 15 years of age. These samples were further investigated using various laboratory indices including electrophoresis.

Results: $\beta$-thalassemia minor was detected in 8 cases with various hematological parameters and electrophortic mobilities. The electrophoretic mobility pattern revealed that the patient had increased $\mathrm{HbA} 2$ and $\mathrm{HbF}$ band and decreased $\mathrm{HbA} 1$ band. Among hematological parameters, the mean hemoglobin was $8.1 \pm 2.3 \mathrm{gm} \%$ in $>15$ years age group and $3.9 \pm 1.7$ in $<15$ years age group, Peripheral smear revealed microcytic, hypochromic, anisopoikilocytic, target cells and solubility test for sickle cell was negative for all samples. The median unconjugated bilirubin level was 1.95 (IQR: 1.6-2.1) in $<15$ yrs and 2.25 (IQR: 1.7-7.7) in $>15$ yrs, the median reticulocyte count was 1.65 (IQR: $0.55-2.3$ ) in $<15$ yrs and 1.8 (IQR: $1-5$ ) in $>15$ yrs, Reticulocyte production Index was less than two, median HbF was 7.5 (IQR: 4.2-25) in $<15$ yrs and 8 (IQR: 1.7-18) $>15$ yrs , median PCV was 23.4 (IQR: 19.5-25.9) in <15 yrs and 14.6 (IQR: 12.2-16.8) in $>15$ yrs. The study also revealed that the $\beta$-thalassemia was predominant among Tharus $(50 \%)$ compare to other ethnicity.

Conclusion: Patients of $\beta$ thalassemia minor showed decrease in hemoglobin, increased unconjugated bilirubin, abnormal peripheral smear, and abnormal hemoglobin pattern on electrophoretogram.
\end{abstract}

Keywords: Beta thalassemia minor, agar gel electrophoresis, HbA2 


\section{Introduction}

Thalassemia is the most common inherited single gene disorder in the world. Around the globe, 4.83 percent carry globin variants, which includes $1.7 \%$ who are heterozygous for alpha and beta thalassemia ${ }^{1}$. The heterozygous state confers a degree of protection against malaria which may be responsible for perpetuating the mutation in malaria endemic regions. In Nepal, the prevalence of Thalassemia is particularly high among the Tharu communities with a gene frequency of 0.8 , where it has decreased malariaassociated morbidity by a maximum of 10 fold $^{2}$.

The normal human adult hemoglobin ( $\mathrm{Hb}) \mathrm{A}(\mathrm{HbA})$ consists of two pairs of globin chains, $\alpha 2 \beta 2$; their synthesis is normally tightly coordinated to ensure equal production. Thalassemia occurs when this balance is disturbed. When there is mutation of gene encoding $\beta$-globin, $\beta$-thalassemia occurs which induces an absence or low-level synthesis of this protein in erythropoietic cells. ${ }^{3}$ It manifests as hemolytic disorders of varying degrees in heterozygote condition but traits are often asymptomatic.

The diagnosis of $\beta$-thalassemia relies on measuring red blood cell indices that reveal microcytic hypochromic anemia, nucleated red blood cells on peripheral blood smear, hemoglobin analysis that reveals decreased amounts of $\mathrm{HbAl}$ and increased amounts of hemoglobin $\mathrm{F}$ (HbF) after age 12 months, and increase in HbA2.Hemoglobin electrophoresis in alkaline medium plays a major role in detecting increased levels of $\mathrm{HbA} 2$ and decreased $\mathrm{HbA} 1$ pattern.

\section{Methods}

A total of 78 blood samples were collected from patients visiting BPKIHS, Dharan to identify red blood cell indices and degree of anemia. From these 78 patients, 8 samples were suspected of $\beta$ thalassemia minor and included in the study. A full history including family history and physical examination was done after taking informed consent of the subjects. The patients were divided in two groups, group A (adult: above 15 years of age) and group B (children below 15 years of age). These 8 samples were investigated further in the Department of Biochemistry, BPKIHS between January 2012 and December 2012. The study was conducted in compliance with the guidelines of ethical committee, BPKIHS, Dharan.

Two $\mathrm{ml}$ of venous blood was obtained in EDTA (ethylene diamine tetracetic acid) vial and another $3 \mathrm{ml}$ allowed to clot in separate vial. The anticoagulated blood was used for performing CBC (Complete Blood Counts), Reticulocyte count, hemoglobin electrophoresis, hemoglobin F estimation, solubility test. Two direct smears were also made in each case. Hemoglobin was measured by cyanomethemoglobin method using spectrophotometer 259 (Sherwood Scientific Ltd U.K). Total cell counts were performed using coulter counter model, differential count and peripheral smear were done using smears obtained. Hemoglobin electrophoresis was carried out after hemolysate preparation from blood samples, buffer used was TRIS EDTA borate buffer at $\mathrm{pH}$ of 8.6 with matched control of normal hemolysate running parallel from cathode to anode applying 5 milli amperes current and the constant voltage of 200 volts. Patients who had received blood transfusion within past 3 months were excluded from study. Bilirubin level was measured by modified DMSO method using Vita Lab Selectra E 311 and solubility test for sickle cells, ${ }^{4} \mathrm{HbF}$ were measured using alkali denaturation test. $^{5}$

\section{Results}

$\beta$-thalassemia minor was detected in 8 cases with significant changes in laboratory parameters (Table 1) and electrophoretic mobility pattern (Table 3 and figure 1). On the basis of electrophoresis pattern, it was revealed that the patient had increased $\mathrm{HbA} 2$ and $\mathrm{HbF}$ band, and decreased HbA1 as depicted in table 3 and figure 1. Solubility tests showed negative results for sickle cells.

The peripheral smear revealed microcytic, hypochromic, anisopoikilocytic, and target cells. Mean hemoglobin concentration was $8.1 \pm 2.3 \mathrm{gm} \%$ in $>15$ years and $3.9 \pm 1.7$ in $<15$ years age group. The median and interquartile range of unconjugated bilirubin was $1.95 \mathrm{mg} / \mathrm{dl}(1.6-2.1)$ in $<15$ yrs and $2.25 \mathrm{mg} / \mathrm{dl}(1.7-7.7)$ in $>15 \mathrm{yrs}$, of Reticulocyte count was $1.65 \%(0.55-2.3)$ in $<15$ yrs and $1.8 \%(1-5)$ in $>15$ yrs, both groups had reticulocyte production Index (RPI) less than two (RPI Index demonstrated in table 2). $\mathrm{HbF}$ was $7.5 \%(4.2-25)$ in $<15 \mathrm{yrs}$ and $8(1.7-18)>15 \mathrm{yrs}$ , and of PCV was $23.4 \%(19.5-25.9)$ in $<15$ yrs and $14.6 \%$ (12.2-16.8)in $>15$ yrs age group (Laboratory parameters are summarized in table 1).

Among ethical distribution, $\beta$-thalassemia minor was significantly identified $(\mathrm{P}<0.05)$ among Tharu patients compare to other groups (Newar, Muslim and Brahmin) as depicted in figure 2 . 
Table 1: Laboratory parameters of Beta-thalassemia Patients

\begin{tabular}{|c|c|c|c|c|c|c|c|c|c|}
\hline \multirow{3}{*}{$\begin{array}{l}\text { SN } \\
1\end{array}$} & \multirow{3}{*}{$\begin{array}{l}\text { Age/Sex } \\
\text { Yrs/Sex }{ }^{1} \\
4 / \mathrm{M}\end{array}$} & \multirow{3}{*}{$\begin{array}{l}\mathrm{Hb}(\mathrm{gm} \%) \\
4.7\end{array}$} & \multicolumn{2}{|c|}{ Bilirubin (mg/dl) } & \multirow{3}{*}{$\begin{array}{l}\text { Reticulocyte } \\
\text { count } \\
1.0\end{array}$} & \multirow{2}{*}{\multicolumn{2}{|c|}{$\begin{array}{l}\text { Iron TIBC } \\
\text { (microg/dl) }\end{array}$}} & \multirow{3}{*}{$\begin{array}{l}\text { HbF } \\
30\end{array}$} & \multirow{3}{*}{$\begin{array}{l}\text { PCV } \\
18.6\end{array}$} \\
\hline & & & \multirow{2}{*}{$\begin{array}{l}\text { Total } \\
2.0\end{array}$} & \multirow{2}{*}{$\begin{array}{l}\text { Indirect } \\
1.5\end{array}$} & & & & & \\
\hline & & & & & & 66 & 298 & & \\
\hline 2 & $12 / \mathrm{F}$ & 5.5 & 2.5 & 1.9 & 2.3 & 62 & 291 & 10 & 26.4 \\
\hline 3 & $5 / \mathrm{M}$ & 1.5 & 2.5 & 2.0 & 0.4 & 94 & 316 & 4 & 24.6 \\
\hline 4 & $6 / \mathrm{M}$ & 3.8 & 2.6 & 2.2 & 2.3 & 52 & 250 & 5 & 22.2 \\
\hline 5 & $27 / \mathrm{M}$ & 7.7 & 2.1 & 1.6 & 2.0 & 96 & 300 & 12 & 16.2 \\
\hline 6 & $18 / \mathrm{M}$ & 5.3 & 2.7 & 2.1 & 0.8 & 90 & 300 & 4 & 17.0 \\
\hline 7 & $28 / \mathrm{F}$ & 11 & 3.0 & 2.4 & 1.6 & 104 & 326 & 20 & 13.0 \\
\hline 8 & $25 / \mathrm{M}$ & 8.4 & 10.4 & 9.5 & 6.0 & 92 & 312 & 1 & 12.0 \\
\hline
\end{tabular}

$1=\mathrm{M}$ (male), $\mathrm{F}$ (female)

Table 2: Reticulocyte production Index of cases

\begin{tabular}{|cc|}
\hline Case number & Reticulocyte production Index(RPI) \\
\hline 1 & 0.3 \\
\hline 2 & 0.8 \\
\hline 3 & 0.04 \\
\hline 4 & 0.6 \\
\hline 5 & 1.0 \\
\hline 6 & 0.3 \\
\hline 7 & 1.2 \\
\hline 8 & 3.0 \\
\hline
\end{tabular}

Figure $1 \mathrm{Hb}$ electrophoresis at alkaline $\mathrm{pH}$ in Agar gel

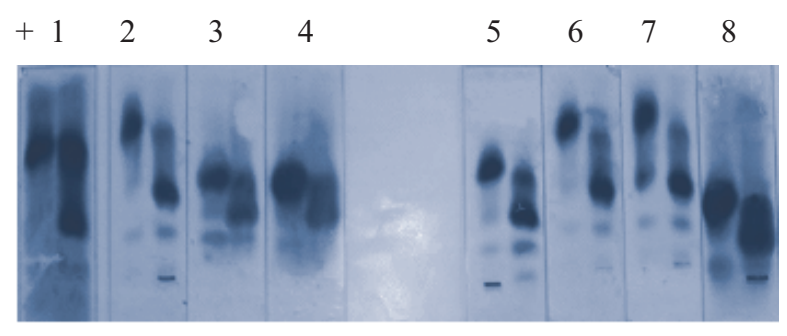

The above figure shows: $\mathrm{Hb}$ electrophoresis at alkaline $\mathrm{pH}$ (8.6) in Agar gel. $\mathrm{Hb}$ (control) is on left side of each slide and patient's sample on right side of each slide, both control and Patient $\mathrm{Hb}$ sample move from cathode towards anode. The control has normal $\mathrm{HbA} 1$ band with no splitting. The patient's sample, shows splitting indicating decreased $\mathrm{HbA} 1$, increased $\mathrm{HbA} 2$ and $\mathrm{HbF}$.
Table 3: Mobility Pattern of Agarose Gel electrophoresis (AGE)

\begin{tabular}{cccll} 
SN & \multicolumn{3}{c}{ Hb electrophoresis } & $\begin{array}{l}\text { Solubility test } \\
\text { for sickle cell }\end{array}$ \\
\hline & HbA1 & HbA2 $\mathrm{HbF}$ & \\
\hline 2 & $\downarrow$ & $\uparrow$ & $\uparrow$ & Negative \\
\hline 3 & $\downarrow$ & $\uparrow$ & $\uparrow$ & Negative \\
\hline 4 & $\downarrow$ & $\uparrow$ & $\uparrow$ & Negative \\
\hline 5 & $\downarrow$ & $\uparrow$ & $\uparrow$ & Negative \\
\hline 6 & $\downarrow$ & $\uparrow$ & $\uparrow$ & Negative \\
\hline 7 & $\downarrow$ & $\uparrow$ & $\uparrow$ & Negative \\
8 & $\downarrow$ & $\uparrow$ & $\uparrow$ & Negative \\
\hline
\end{tabular}

Figure 2 Ethnicity distributions among $\beta$ thalassemia minor cases

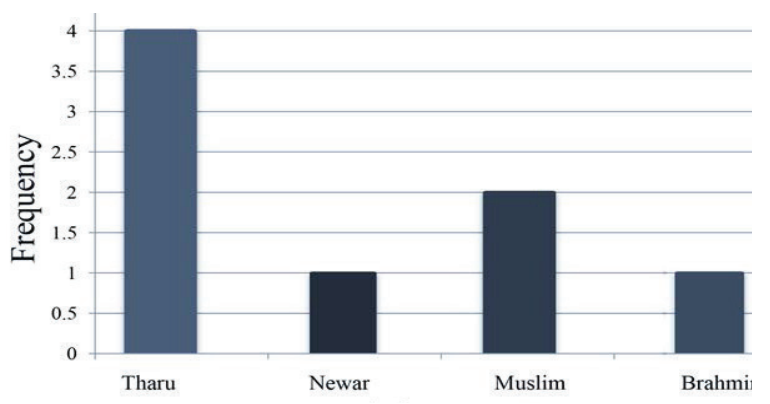




\section{Discussions}

A total of 8 samples suspected of $\beta$ thalassemia minor were included in the study. Prior to laboratory investigation, clinical history was obtained from these patients. The most common clinical presentation was pallor and Icterus and all patients had spleen and liver enlargement. One patient had been splenectomized. One gave the history of consanguinity of his parents. A study done on consanguinity in Iran showed $40.6 \%$ of families with beta-thalassemic patients were outcome of first-cousin marriages ${ }^{6}$.

Various biochemical parameters were done to detect and find cause of anemia. Reticulocyte and Reticulocyte production index (RPI) was assessed and RPI less than two indicating either maturation defects or hypoproliferative anemia was found. Further confirmation was done by peripheral smear which revealed microcytic, hypochromic, anisopoikilocytic, and target cells. These findings indicated maturation defect. Another important factor was to differentiate iron deficiency anemia and B Thalassemia minor as both present as anemia and iron deficiency anemia can also be a maturation disorder. Family history of Thalassemia, ethnic group, and mentzer index more than 13 pointed towards Thalassemia ${ }^{7,8}$. Final confirmation of the diagnosis was done utilizing Hemoglobin electrophoresis using alkaline media. This technique is able to differentiate $\mathrm{Hb}$ variants as $\mathrm{HbS}, \mathrm{HbA} 1, \mathrm{HbA} 2, \mathrm{HbF}$ etc. Our electrophoretic finding suggested increased $\mathrm{HbA} 2 /$ $\mathrm{HbS}$ and $\mathrm{HbF}$ band, and decreased $\mathrm{HbA} 1$. HbA2 or $\mathrm{HbS}$ bear same charges which creates diagnostic dilemma. But occurrence of $\mathrm{HbS}$ in people in this geographical region is $\operatorname{rare}^{8,9}$. Besides, Solubility tests showed negative results for sickle cells. Further differentiation of variants can be done using citrate gel electrophoresis in acid medium. However, this was not performed in our study.

\section{Conclusion}

Nepal is defined as Thalassemia zone by World Health Organization. Laboratory continues to play a crucial role for detection of Thalassemia cases with electrophoresis a crucial test for diagnosis. However, investigations regarding carrier detections, molecular diagnostics, genetic counseling, and prenatal diagnosis are yet to be ventured. Variability of clinical severity attributable to interactions with $\alpha$-thalassemia is another field to be explored.

Conflict of interests: The authors declare that they have no conflict of interests.

\section{References}

1. Rund D, Rachmilewitz E. $\beta$ thalassemia N Engl J Med 2005; 353:1135-1146

2. Modiano G, Morpurgo G, Terrenato L. Protection against malaria morbidity: near-fixation of the alphathalassemia gene in a Nepalese population. Am J Hum Genet 1991; 48:390-397.

3. Weatherall DJ. Phenotype-genotype relationships in monogenic disease: lessons from the thalassaemias. Nature Reviews Genetics 2001; 4:245-255.

4. Cook A and Raper A B. The solubility test for HbS: A cheap and rapid method. Medical Laboratory Technology 1971; 28:373-376.

5. Jonxis and Huisman. The detection and Estimation of Fetal Hemoglobin by means of the Alkali denaturation test. Blood Journal, Hematology 1956; 11: 1009-1018.

6. Pooya asadi A, Doroudchi M. Thalassemia major and consanguinity in Shiraz city, Iran. Turk J Haematol 2004; 21(3):127-130.

7. Morpurgo G, Terrenato L. Protection against malaria morbidity: near-fixation of the alpha-thalassemia gene in a Nepalese population. Am J Hum Genet 1991; 48:390-397.

8. Sakai Y, kobayashi S. Molecular analysis of alphathalassemia in Nepal: correlation with malaria endemicity. J Hum Genet 2000; 45(3):127-132

9. Majhi S, Mishra A. Detection of $\beta$-thalassemia (homozygous) by hemoglobin electrophoresis on agar gel and citrate agar medium: a case report. Nepal Medical College Journal 2007; 9(1). 